\title{
International Real Estate Economics
}

Piyush Tiwari and Michael White

2010

Palgrave Macmillan

215 pp.

ISBN 978--0--230--50758--6 paperback

International Real Estate economics is a new field of study in the wider Real Estate subject area, both for what concerns teaching and research. The authors' premise is that, in the wider context of global economic change and international economic integration, the past 30 years have witnessed the most significant internationalization of the real estate industry. Despite such relevance, there is no other text-book which is systematically focused on real estate use and investment beyond the domestic market. Tiwary and White aim to fill such gap with this textbook.

The increasing internationalization of trade and capital flows naturally implies that real estate users and investors look beyond the national market and, with this respect, a particular role should be played by multinational firms. At the same time, real estate 
markets maintain specific national features that may act as a barrier to internationalization. The analysis of such complex balance is the ultimate aim of the book which, indeed, constitutes a useful and commendable contribution to shed light on a new and complex subject.

The book relies extensively on a descriptive institutional approach, which is common in a certain literature in real estate and only few fundamental economic models are formally presented. Rather than being structured around formal models, as typical in economics textbooks, most of the chapters are rather developed around extensive and logically organized reviews of literature.

The aim and organization of the book is clearly exposed in Chapter 1 . Chapter 2 presents, in an intuitive way, some fundamental theories of international trade: the economic reasons for trade, the concept of comparative advantage, the Hecksher-Ohlin trade model through a concise diagrammatic presentation, the inter-temporal trade model, the Dunning Eclectic paradigm, the Porter's model of competitive advantage. The chapter concludes with a concise presentation of the evidence on international trade, capital flows and transnational firms. It is argued that real estate will enter this "big picture" because transnational firms need real estate space and because those needs may be better answered by transnational real estate service providers. 
Similarly, chapter 3 presents, in an intuitive way, the fundamental theoretical framework in financial economics that can rationalize international real estate investments: the CAPM, the role of financial deregulation in international diversification, a review of the literature on direct and indirect real estate investment and international returns. As an alternative to this standard neo-classical framework, it then presents the more institutional approach to real estate with a review of some important papers which can make sense of one of the main messages of the authors: the fact that, although there are in principle benefits from diversification, it may be in practise difficult to achieve because of many institutional features and market imperfections acting as barriers.

Largely based on market reports, chapter 4 presents an outlook on the current state of the property market activity: size, composition, use markets in the key countries. It also presents intriguing results of an analysis (done by RREEF) on international cycles. Referring to similar market reports (like those of CBRE and ING), it presents some evidence on international investment activity, performance, investors' profile, development and financing.

Building on the institutional approach introduced in chapter 3, chapter 5 discusses the role and features of real estate service providers (RESP) through an extensive review of literature. The case for internationalization of RESP is mainly discussed with reference to the analysis of their (evolving) culture and relationship with local markets. 
The remaining chapters present extensive evidence on the different geographic areas. Chapter 6 focuses on Europe: it presents evidence on performance, an institutional analysis of the market maturity and the transparency of the various countries and a more specific institutional analysis of Eastern European markets. Chapter 7 focuses on the Asia-Pacific region: after an overview of the economic context, it discusses the impact of globalization with data on FDI, the process urban transformation in Tokio, Seul, Singapore and China, the data on current market performance, the property market institutions in Japan, Taiwan, Hong Kong, South Korea, Mainland China, India. Chapter 8 focuses on North America: it describes the institutional features of REITs and mutual funds and presents evidence on the historical performance of all property sectors. Chapter 9 focuses on Latin America: after an overview of the economic context, it discusses the institutional features, performance, analysis of the maturity and transparency of various markets in the region. Chapter 10 summarizes the main findings and outlines some final thoughts on the extent of international integration, the interpretation of international cycles and the future market outlooks.

This book is surely a very interesting, informative and relevant read for everyone interested in real estate economics, markets and investment, especially given the increasing relevance of the international dimension and the lack of similar broad analyses. The intuitive presentation-style and accessibility to students not trained in standard economics makes it an ideal textbook for undergraduate and postgraduate courses in Real Estate degrees, as well as a very useful additional reading for more formal courses in Urban and Real Estate economics. 
As admitted by the authors, the book opens a lot of important questions about the extent of international integration and the driving forces behind international real estate cycles without necessarily completely answering them. My view is that this does not to be considered a limitation of the book, but rather as an intrinsic feature of the institutional approach and method. In fact, those are "big" questions that current research in real estate economics is still trying to address and the more descriptive institutional approach cannot offer the rigorous, general and empirically testable framework that characterizes standard economics.

With this respect, this book interestingly shows that rigorous economics models could have a lot to offer towards a more precise interpretation of the well described relevant and complex international dynamics. Therefore, rather than being the definitive account of the field, this book could interestingly inspire future research and textbooks in real estate economics and finance where the interesting questions found by the institutional approach should be rigorously answered by empirical and theoretical analyses. At the same time, as research progresses, also the future editions of this textbook could be enriched by new economic models in the more theoretical parts and case studies in the more descriptive parts.

Tommaso Gabrieli

Real Estate and Planning, Henley Business School, University of Reading, UK. 